\title{
Design Fire Characteristics for Probabilistic Assessments of Dwellings in England
}

\author{
Charlie Hopkin (D* and Yong Wang, School of Mechanical, Aerospace and Civil \\ Engineering, The University of Manchester, Manchester M13 9PL, UK \\ Michael Spearpoint, OFR Consultants, Sevendale House, Level Street, \\ Manchester M1 1JA, UK \\ Danny Hopkin, OFR Consultants, Bicester Innovation Centre, Suite 112, \\ Commerce House, Telford Road, Bicester OX26 4LD, UK
}

Received: 29 August 2019/Accepted: 29 October 2019

\begin{abstract}
In England, there are no fixed requirements on the parameters adopted when considering residential design fires, and analyses undertaken are often deterministic with limited consideration given to probabilistic assessments and the sensitivity of parameters. The Home Office dwelling fires dataset has been analysed, considering the fire damage area and the time from ignition to fire and rescue service arrival. From this, lognormal distributions for the maximum heat release rate (HRR) and fire growth rate of residential fires have been approximated. The mean maximum HRR ranges from $900 \mathrm{~kW}$ to $1900 \mathrm{~kW}$, with a standard deviation ranging from $2000 \mathrm{~kW}$ to $3700 \mathrm{~kW}$, depending on property type and room of fire origin. The mean growth rate, assuming a $t^{2}$ relationship, ranges from $0.0022 \mathrm{~kW} / \mathrm{s}^{2}$ to $0.0034 \mathrm{~kW} / \mathrm{s}^{2}$, with a standard deviation ranging from $0.0071 \mathrm{~kW} / \mathrm{s}^{2}$ to $0.0132 \mathrm{~kW} / \mathrm{s}^{2}$. When considering incidents which result in immediate fire and rescue service call out following ignition, the mean growth rate increases to a range of $0.0058 \mathrm{~kW} / \mathrm{s}^{2}$ to $0.0088 \mathrm{~kW} / \mathrm{s}^{2}$. As a result of the analyses, design fire distributions are provided which can be adopted for probabilistic assessments. For deterministic analyses, it is proposed that an approximate 95th percentile fire may be adopted, aligning with a medium growth rate of $0.0117 \mathrm{~kW} / \mathrm{s}^{2}$ and a maximum fuel-limited $\mathrm{HRR}$ in the region of $3800 \mathrm{~kW}$ to $4400 \mathrm{~kW}$, depending on whether the dwelling is a house or an apartment. A 95th percentile design fire broadly aligns with values already specified in guidance, helping to substantiate the existing recommendations.
\end{abstract}

Keywords: Residential, Dwellings, Design fire, Fire size, Heat release rate, Fire growth rate

\section{Introduction}

The SFPE Handbook of Fire Protection Engineering [1] recommends that a series of steps should be taken when proposing a design fire scenario, such as determining the location of the fire, the potential hazards, the systems impacting on the

* Correspondence should be addressed to: Charlie Hopkin, E-mail: charlie.hopkin@postgrad.manchester.ac.uk 
fire, occupant response and so on. One key aspect of this is to consider the type of fire which may occur, which can be characterised by several parameters, including its area, growth rate, maximum heat release rate (HRR) and burning duration. These parameters are typically quantified through the application of various research publications and guidance documents.

When developing fire safety strategies and undertaking fire and smoke modelling for residential design, fire engineers are often required to make an 'engineering judgement' on what represents a 'reasonable worst-case' for a design fire scenario, taking into consideration the aforementioned parameters. This can be a challenging judgement to make, as the engineer can only make an informed presumption on the quantity and type of combustibles in a residential space where variations can occur due to complex factors, such as demographics and culture. In addition, in many circumstances, the buildings being analysed have yet to be built. In England, there are no fixed requirements on what parameters should be selected for a residential design fire, with standards and guidance documents providing differing recommendations, noted in the literature review of this paper. Furthermore, analyses undertaken are often deterministic in nature, where fixed design fire parameters are adopted, and limited consideration is given to the sensitivity or potential distribution of these parameters. This means that the level of safety achieved is not quantifiable, i.e. it is without a quantitative safety target, and that the demonstration of an adequate level of safety can differ between designers within the same jurisdiction [2].

Discussion on fire scenarios in the SFPE Handbook of Fire Protection Engineering [1] mentions that, where a severe quantity of fuel is expected, an $80^{\text {th }}$ to $95^{\text {th }}$ percentile (e.g. in the distribution of fuel load densities) should be considered. However, to be able to assess these percentiles when proposing design fire scenario, appropriate distribution parameters need to be known.

The Home Office dwelling fires dataset (DFD) [3] provides data on all recorded fire events in England from 2010 to the present day (typically released annually). The dataset provides information for recorded fire events, including dwelling type, occupancy type, fire damage area, total damage extent and fire and rescue service (FRS) arrival time. The DFD understandably does not include unreported fires (i.e. fires not resulting in FRS call out). It may therefore be considered that the DFD represents only the most severe fires which warrant FRS intervention, thus presenting a potential hazard to life. This paper proposes that the data provided in the DFD, in particular the fire damage area and FRS arrival time, can be used to estimate probabilistic distributions of residential fires, focussing on parameters for the maximum HRR and fire growth rate.

\section{Liferature Review}

\subsection{Common Guidance-Based Design Values}

In England, there are several design and guidance documents in which design values for residential fires are discussed. These documents include the Smoke Control Association (SCA) Guide [4], Building Research Establishment (BRE) document 
'Smoke Ventilation of Common Access Areas of Flats and Maisonettes' (BD 2410) [5] and British Standard Published Document PD 7974-1 [6]. The SCA Guide [4] states that for non-sprinkler protected residential buildings, a maximum HRR generated may be of the order of $2 \mathrm{MW}$ to $6 \mathrm{MW}$ (following a growth period), depending upon enclosure size and available ventilation. Also referenced in the SCA Guide is the previous work undertaken by the BRE on ventilation provisions in blocks of flats (referred to hereafter as apartments). The BRE study BD 2410 [5] analysed the recommended provisions for the protection of stairs in the subsequent 2006 revision of Approved Document B (ADB) Vol. 2 [7] to establish whether they could achieve adequately safe conditions. In all instances nonsprinklered fires were assumed and the analyses adopted a 1.0 MW steady-state HRR and a $2.5 \mathrm{MW}$ steady-state HRR to represent conditions potentially encountered upon initial arrival of the FRS and during firefighting operations. However, the severity of these conditions in the context of real fire incidents or experimental data is unclear.

In addition to the maximum HRR, standard international design guidance also makes recommendations on the growth rate of a fire, typically the rate in which the fire grows to its maximum HRR. For dwellings, PD 7974-1:2003 [8] recommends a medium growth rate $\left(0.0117 \mathrm{~kW} / \mathrm{s}^{2}\right)$ for a characteristic $\mathrm{t}^{2}$ fire growth curve, as does CIBSE Guide E [9], while in comparison New Zealand verification method C/VM2 [10] generally proposes a fast growth rate $\left(0.0469 \mathrm{~kW} / \mathrm{s}^{2}\right)$ for all buildings irrespective of occupancy type.

Hopkin et al. [11] undertook a review of design values adopted for HRRPUA, including specific consideration of residential occupancies. Aside from guidancebased values, the review refers to three sources of information, only one of which specified a distribution/range for HRRPUA, suggesting there is a limited quantity of data available to determine reasonable distributions for residential design. Guidance document EN 1991-1-2 [12] recommends a HRRPUA for residential occupancies of $250 \mathrm{~kW} / \mathrm{m}^{2}$. Law [13] suggested a value of $290 \mathrm{~kW} / \mathrm{m}^{2}$ for both offices and residential buildings and Klote and Milke [14] proposed a design value of $500 \mathrm{~kW} / \mathrm{m}^{2}$, in reference to work by Fang and Breese [15]. Fang and Breese undertook sixteen experiments for fires in residential occupancies, for $3.3 \mathrm{~m}$ wide, $3.3 \mathrm{~m}$ long by $2.4 \mathrm{~m}$ high enclosures considered representative of typical occupancies. The type of furniture included was generally representative of a living room arrangement, with seating, tables and bookcases. For these experiments, the maximum HRRPUA varied from $320 \mathrm{~kW} / \mathrm{m}^{2}$ to $570 \mathrm{~kW} / \mathrm{m}^{2}$.

\subsection{The Maximum Heat Release Rate as a Function of Fire Damage Area}

Of the data available in the dwelling fire dataset, fire damage area is that which is most closely able to provide an indication of the maximum HRR achieved by residential fire events. Previous work by Morgan and Hansell [16] used similar historical data to consider fire sizes and sprinkler effectiveness in offices, where it stated that a fire can be assumed to burn in two ways, dependent on either the fuel being burned ('fuel-bed controlled') or dependent on the quantity of air available ('ventilation controlled'). For 'fuel-bed controlled' fires, Morgan and Hansell proposed 
that the maximum HRR of the fire $\left(Q_{f}, \mathrm{~kW}\right)$, based on the burning rate/floor area covered of wood cribs, could be represented as:

$$
Q_{f}=260 \mathrm{~A}_{f}
$$

where $260 \mathrm{~kW} / \mathrm{m}^{2}$ is the adopted HRRPUA and the area of the fire $\left(\mathrm{A}_{f}, \mathrm{~m}^{2}\right)$ was assumed to be equivalent to the fire damage area $\left(\mathrm{A}_{f d}\right)$, stating that "the fire-damaged area is closely related to the actual size of the fire" [16]. However, it is possible that equating the full fire damage area to the area of the fire may over and under-estimate (e.g. in instances of zero fire damage) the HRR in certain circumstances, with Almås [17] adopting an approach of assuming the burning area is $50 \%$ of the fire damage area when defining risk-adjusted design fires.

Yuen and Chow [18] expanded on the work of Morgan and Hansell by considering the potential variation in the fuel load and therefore the variation in HRRPUA, as well as variation in heat loss due to the impact of sprinklers. Yuen and Chow applied the Monte Carlo method to the equation below, for Morgan and Hansell's original data for fire damage area, to generate a range of potential design 'fire sizes':

$$
Q_{h}=\dot{Q}^{\prime \prime} C_{h} C_{s} \mathrm{~A}_{f d}
$$

where the heat release excluding losses $\left(Q_{h}\right)$ was a function of the HRRPUA of the fuel bed $\left(\dot{Q}^{\prime \prime}\right)$, heat loss to compartment boundaries $\left(C_{h}\right)$ and reduction in heat release due to the presence of sprinklers $\left(C_{S}\right)$. The HRRPUA was modelled as being uniformly distributed between $90 \mathrm{~kW} / \mathrm{m}^{2}$ and $360 \mathrm{~kW} / \mathrm{m}^{2}$, ranging from a low ratio of fuel surface to fuel mass to a high ratio from the work of Theobald [19]. A constant of one-third was adopted for $C_{h}$ and $C_{s}$ was varied between 0.4 and 0.6 , based on the estimations of Morgan and Hansell, where the energy lost to sprinkler spray was determined to be in the region of $40 \%$ to $60 \%$ [16]. Excluding heat losses to boundaries and sprinkler spray, the HRR can be simplified to:

$$
Q_{f}=\dot{Q}^{\prime \prime} \mathrm{A}_{f d}
$$

In equating fire damage area to HRR, both the works of Morgan and Hansell and that of Yuen and Chow source a limited amount of data, focussing exclusively on the work of Theobald [19] which considered burning rate per unit area of fire for incidents in industrial premises. As discussed by Hopkin et al. [11], Theobald similarly determined his values using approximated fire damage area from fire incident reports. While there is limited research available which confirms the relationship between fire damage area and HRR, its application seems intuitively reasonable. It also forms one of the only means for measuring the 'size' of fire incidents, where standard experimental approaches to measuring HRR (e.g. considering calorimetry or mass loss) are not possible. 


\subsection{Fire Growth Rate}

Holborn et al. [20] equated the fire growth rate based on fire investigation data, with 1991 samples, gathered in the greater London area. Fire damage area was again assumed to be consistent with the fire area, based on a HRRPUA $\left(\dot{Q}^{\prime \prime}\right)$ of $250 \mathrm{~kW} / \mathrm{m}^{2}$, similar in approach to that described by Morgan and Hansell [16]. Holborn et al. proposed that the average fire growth parameter $\alpha\left(\mathrm{kW} / \mathrm{s}^{2}\right)$ could be estimated by adopting a least squares fit of a $t^{2}$ growth rate based on the fire damage area when the fire was discovered $\left(\mathrm{A}_{1}\right)$ compared to when the FRS arrived $\left(A_{2}\right)$, and the time intervals from ignition to discovery $\left(t_{1}\right)$ and ignition to FRS arrival $\left(t_{2}\right)$. It was also assumed that the fire area was equal to zero at the time of ignition (i.e. the curve passes through the origin). This relationship was summarised by Holborn et al. as:

$$
\alpha=\frac{\dot{Q}^{\prime \prime}\left(\mathrm{A}_{1} t_{1}^{2}+A_{2} t_{2}^{2}\right)}{t_{1}^{4}+t_{2}^{4}}
$$

From this it was determined, using estimated lognormal distribution parameters, that dwelling fires had a mean fire growth rate of $0.0060 \mathrm{~kW} / \mathrm{s}^{2}$ with a 95th percentile $0.0240 \mathrm{~kW} / \mathrm{s}^{2}$. For comparison, fire growth rate values recommended in PD 7974-1 [6] range from a slow growth rate of $0.0029 \mathrm{~kW} / \mathrm{s}^{2}$ to an ultra-fast growth rate of $0.1876 \mathrm{~kW} / \mathrm{s}^{2}$, with a medium growth rate $\left(0.0117 \mathrm{~kW} / \mathrm{s}^{2}\right)$ commonly adopted for the modelling of dwelling fires in England, representing the 91st percentile of the Holborn et al. distribution. The C/VM2 [10] recommended fast growth rate fire $\left(0.0469 \mathrm{~kW} / \mathrm{s}^{2}\right)$ is equivalent to the 98 th percentile of Holborn et al.

Baker et al. [21] determined a residential growth rate distribution using the zone modelling software B-RISK. A residential occupancy based on experiments undertaken in Sweden was modelled using probabilistic inputs for the 'design fire generator' (DFG) and by applying the Monte Carlo method. The outcome of the modelling indicates that a fire growth rate distribution could approximated to a triangular distribution, with a minimum of $0 \mathrm{~kW} / \mathrm{s}^{2}$, a maximum of $0.4120 \mathrm{~kW} / \mathrm{s}^{2}$ and a mode of $0.0326 \mathrm{~kW} / \mathrm{s}^{2}$.

Nilsson et al. [22] discuss the quantifying of fire growth rates using statistical and empirical data for fire incidents in commercial buildings in Sweden, where the distribution for fire growth rate was approximated by considering the object first ignited recorded in fire incidents in the context of $\mathrm{t}^{2}$ growth rates derived from literature and experimental data. As with Holborn et al., the growth rate was approximated to be lognormally distributed with a mean of $0.0110 \mathrm{~kW} / \mathrm{s}^{2}$ for accidental fires. It was calculated that a fast growth rate of $0.0469 \mathrm{~kW} / \mathrm{s}^{2}$ covers $97 \%$ of accidental fires and $91 \%$ of fires including arson.

Deguchi et al. [23] determined the growth rate of Japanese fire incidents between 1995 and 2008, adopting a method similar to that described by Holborn et al., where the fire damage area was considered in the context of the time for the FRS to attack the fire, for a fixed HRRPUA of $244 \mathrm{~kW} / \mathrm{m}^{2}$ for residential fires. They presented a lognormal residential growth rate distribution with a mean of $0.0524 \mathrm{~kW} / \mathrm{s}^{2}$ with a standard deviation of $0.0600 \mathrm{~kW} / \mathrm{s}^{2}$, a value much greater 
than that observed by Holborn et al. and Nilsson et al. However, this growth rate will have been influenced by Deguchi et al. limiting their study to incidents where fire damage area exceeded $1 \mathrm{~m}^{2}$ and to incidents where the time from the "break out" of the fire to the time that the FRS began to start spraying water was less than $20 \mathrm{~min}$.

Table 1 provides a summary of parameters for the above distributions identified in the literature. There is a wide variation between the parameters of each distribution, which will be influenced by the different analytical methods and the different datasets/jurisdictions. It is therefore beneficial to conduct a detailed study for more recent data provided in the DFD, to observe whether parameters identified from this data are comparable to the previous studies.

\section{The Dwelling Fires Dataset}

\subsection{Fire Damage Area}

The DFD provides the fire damage area (or 'fire damage extent') for each fire incident, where the fire damage area represents the total horizontal area damaged by the flame or by heat [24]. For the fire damage area, the dataset guidance specifies that for incidents resulting from fire spread, the extent of all area affected is included. If both the floor and ceiling are damaged, the region with the greatest amount of damage is included. The total aggregate of all horizontal damage is recorded; for example, if multiple floors are damaged, the total area of all floors is given. Vertical damage, such as on walls, is not considered, but any horizontal area occupied by damaged contents is included.

The fire damage area by percentage of fires for accidental dwelling fires (limited to the room of fire origin) from 2010 to 2017 is shown in Fig. 1a, where the damage is categorised into different bands (from $0 \mathrm{~m}^{2}$ to over $1000 \mathrm{~m}^{2}$ ), with the range of each band increasing as the recorded fire damage area becomes larger. It can be observed that most of the fires $(93 \%)$ result in a fire damage area less than $5 \mathrm{~m}^{2}$. When considering all accidental fires (i.e. not just those limited to the room

\section{Table 1}

Probabilistic Fire Growth Rate Distribution Parameters Determined in Liferature

\begin{tabular}{llllll}
\hline References & Distribution type & $\begin{array}{c}\text { Mean/mode } \\
\left(\mathrm{kW} / \mathrm{s}^{2}\right)\end{array}$ & $\begin{array}{c}\text { SD } \\
\left(\mathrm{kW} / \mathrm{s}^{2}\right)\end{array}$ & $\begin{array}{c}\text { Minimum } \\
\left(\mathrm{kW} / \mathrm{s}^{2}\right)\end{array}$ & $\begin{array}{c}\text { Maximum } \\
\left(\mathrm{kW} / \mathrm{s}^{2}\right)\end{array}$ \\
\hline Holborn et al. [20] & Lognormal & 0.0060 & 0.0450 & - & - \\
Baker et al. [21] & Triangular & 0.0326 & - & 0.0000 & 0.4120 \\
Nilsson et al. [22] & Lognormal & 0.0110 & 0.0170 & - & - \\
Deguchi et al. [23] & Lognormal & 0.0524 & 0.0600 & - & - \\
\hline
\end{tabular}

Any parameters left blank are not required when generating the specified distribution type 


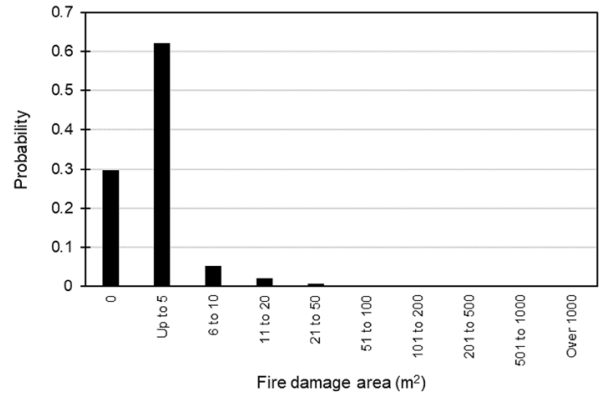

a Probability bands

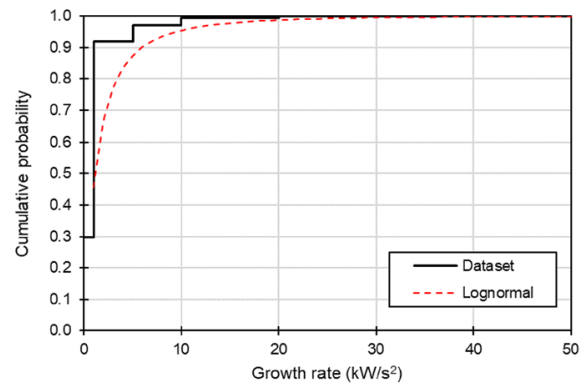

b $\mathrm{CDF}$

\section{Figure 1. Probabilities of fire damage area for fires limited to the room of fire origin, extracted from DFD.}

of fire origin), this value decreases to $84 \%$. For the analyses discussed in this paper, fires limited to the room of origin have been selected as the most appropriate dataset for considering circumstances where the fire is limited by the enclosure, such as during the initiation and early development of the fire.

PD 7974-7:2003 [25], 'application of fire safety engineering principles to the design of buildings using probabilistic risk assessment', indicates that older data from 1979 to 1987 is available with a greater degree of precision in fire damage area (e.g. $0 \mathrm{~m}^{2}$ to $1 \mathrm{~m}^{2}, 2 \mathrm{~m}^{2}$ to $4 \mathrm{~m}^{2}$ etc.). However, data for dwellings and residential buildings is not provided. As part of the revision of PD 7974-7:2019 [26], Manes and Rush [27] undertook an evaluation of the data in PD 7974-7:2003 in the context of US fire statistics, where it was determined for residential buildings that the average fire damage for sprinkler protected residential buildings is $4.9 \mathrm{~m}^{2}$ and for non-sprinkler protected residential buildings $35.7 \mathrm{~m}^{2}$, the latter value being much greater than the average fire damage area determined from the DFD. In contrast to the US data, the DFD does not differentiate between buildings with and without sprinkler protection, but the properties surveyed in 2013-2014 as part of the English Housing Survey [28] indicate that less than $0.3 \%$ of dwellings are sprinkler protected, suggesting that the DFD will have limited representation of fire incidents involving sprinklers. In a previous assessment on the effectiveness of sprinklers in residential premises by Williams et al. [29], it was assumed that UK fire statistics for dwellings were representative of non-sprinklered incidents only.

Figure $1 \mathrm{~b}$ provides a cumulative probability density function (CDF) for the fire damage area of accidental dwelling fires limited to the room of fire origin. As the data for fire damage area of the DFD is presented as a range, the mid-point between the upper and lower bounds has been adopted for all bin ranges except for damage greater than $1000 \mathrm{~m}^{2}$ (where the known lower bound is adopted). It is found that the data broadly follows a lognormal distribution with a mean fire damage area of $2.62 \mathrm{~m}^{2}$ and a standard deviation of $5.37 \mathrm{~m}^{2}$. As can be observed from Fig. 1b, the lognormal distribution over-predicts the fire damage area compared to the data. 


\begin{tabular}{|c|c|c|c|c|}
\hline Dwelling type & Number of incidents & Room type & Mean $\left(\mathrm{m}^{2}\right)$ & $\mathrm{SD}\left(\mathrm{m}^{2}\right)$ \\
\hline \multirow[t]{4}{*}{ Houses } & 75,610 & Kitchen & 2.47 & 5.04 \\
\hline & 9511 & Bedroom & 4.36 & 7.18 \\
\hline & 9810 & Living room & 3.54 & 6.61 \\
\hline & 94,931 & All rooms & 2.77 & 5.51 \\
\hline \multirow[t]{4}{*}{ Apartments } & 38,810 & Kitchen & 2.02 & 4.36 \\
\hline & 3610 & Bedroom & 3.98 & 8.66 \\
\hline & 3470 & Living room & 3.61 & 6.56 \\
\hline & 45,890 & All rooms & 2.30 & 5.06 \\
\hline All dwellings & 140,821 & All rooms & 2.62 & 5.37 \\
\hline
\end{tabular}

Table 2 provides the mean and standard deviation fire damage area for fire incidents where fire damage is limited to the room of fire origin. The results are separated out by room of fire origin and dwelling type, focussing on three main room types (kitchen, bedroom and living room) and two main dwelling types (houses and apartments). The mean and standard deviation have been calculated by assuming that that each data bin correlates with the mid-point of the range, as per the distribution shown in Fig. $1 b$.

A direct comparison of means and standard deviations broadly indicates that apartment-based fires result in a lower fire damage area than houses. For individual rooms, bedrooms are shown to produce the greatest mean fire damage area, followed by living rooms and then kitchens. This may in part be a function of the room size, with kitchens typically being smaller than living rooms, for example [30].

\subsection{Fire and Rescue Service Arrival Time}

The DFD provides three approximate time periods for the development of the fire: "ignition to discovery", "discovery to call" and "response time". Ignition to discovery is described as "the approximated time elapsed from the ignition of the fire to its discovery"; discovery to call is described as "the approximate time elapsed from the discovery of the fire to when the call was made to the emergency services"; and response time is described as "the time between the call being made and the first fire vehicle attending the scene" [24]. It could therefore be assumed that these three values combined would provide an indication of the time from fire ignition to the time of FRS arrival, collectively referred to herein as the 'FRS arrival time' (not to be confused with the FRS response time).

Figure 2a shows the DFD bands and associated probabilities for ignition to discovery and discovery to call times, while Fig. $2 \mathrm{~b}$ shows the bands and probabilities for the response time. It can be observed that the bands for ignition to discovery and discovery to call are much wider than for the response time, likely 


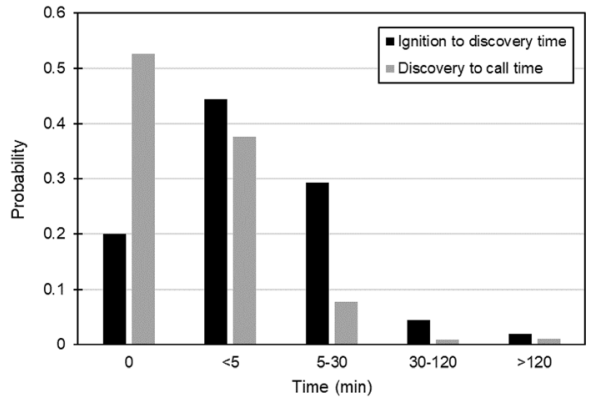

a Ignition to discovery and discovery to call time

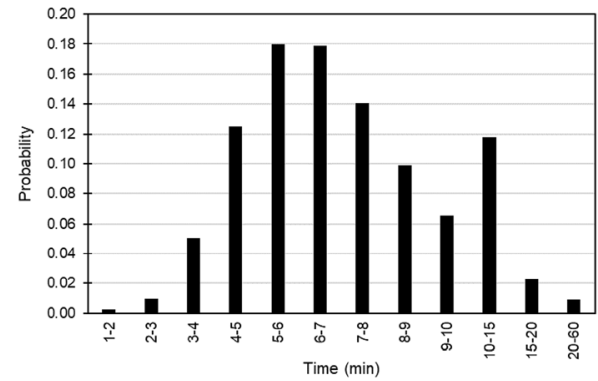

b Response time

Figure 2. Ignition to discovery time, discovery to call time and response time, extracted from DFD. Data bands shown are those provided in the DFD.

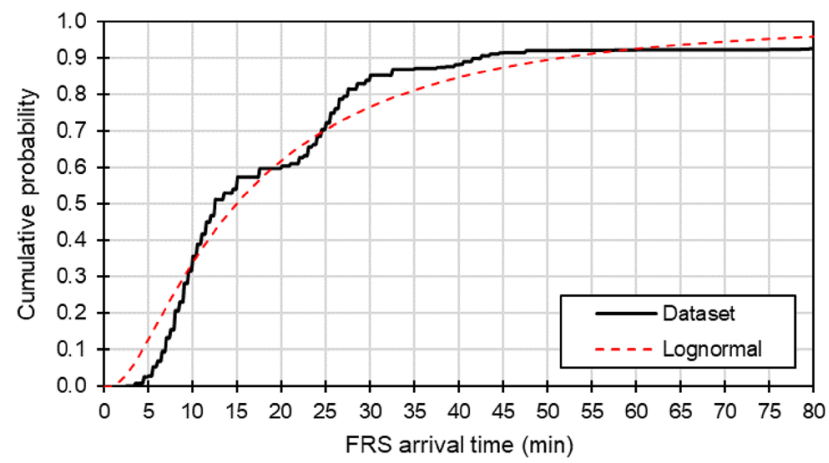

Figure 3. CDF for FRS arrival time.

due to the latter being easier to quantify as part of the fire investigation data recording process.

Combining the times (using the mid-point) to generate the FRS arrival time produces the PDF shown in Fig. 3, with a mean of $1422 \mathrm{~s}$ (23.7 min) and a standard deviation of $1749 \mathrm{~s}$ (29.2 min).

\section{Calculation Methods}

\subsection{Maximum Heat Release Rate}

It is proposed that a distribution of the maximum HRR can be approximated by adopting the method of Morgan and Hansell [16] and Yuen and Chow [18], shown previously in Eq. 3, assuming a stochastic range for the HRRPUA of the fire damage area. A uniform distribution from $320 \mathrm{~kW} / \mathrm{m}^{2}$ to $570 \mathrm{~kW} / \mathrm{m}^{2}$ has been applied for the HRRPUA, where these values are taken from the experiments of Fang and Breese [15]. Therefore, the sampled HRRPUA can be multiplied by the fire damage area for each DFD incident to determine a resultant maximum HRR. 
The calculated maximum HRR will be influenced by the size and arrangement of the enclosure (in this instance, the room of fire origin). It may be expected that the fire damage area is more likely to be 'limited' for smaller rooms when compared to larger rooms, where in the latter there is potential for a greater quantity of combustibles and a greater likelihood of fire spread. Given this relationship, it would be beneficial to consider the fire damage area and resultant maximum HRR as a function of the room area, but this information is not provided in the DFD and therefore the relationship cannot be explored further.

\subsection{Fire Growth Rate}

Revisiting the method of Holborn et al. [20] and Deguchi et al. [23] using the data available in the DFD, a new fire growth rate distribution can be approximated from the time of ignition to the FRS arrival time. This new approximated distribution also takes into account the variability of HRRPUA, where Holborn et al. and Deguchi et al. assumed $250 \mathrm{~kW} / \mathrm{m}^{2}$ and $244 \mathrm{~kW} / \mathrm{m}^{2}$ fixed values, respectively. However, as the dwelling fire dataset does not provide data on the fire damage area upon discovery, the approximation has to be simplified to the following:

$$
\alpha=\frac{\dot{Q}^{\prime \prime} \mathrm{A}_{f d}}{\left(t_{0}+t_{1}+t_{2}\right)^{2}}
$$

where $\dot{Q}^{\prime \prime}$ is the (stochastic) HRRPUA $\left(\mathrm{kW} / \mathrm{m}^{2}\right), \mathrm{A}_{f d}$ is the fire damage area $\left(\mathrm{m}^{2}\right)$, $t_{0}$ is the ignition to discovery time (s), $t_{1}$ is the discovery to call time (s) and $t_{2}$ is the FRS response time (s). Again, in all instances the mid-point of the statistical bin ranges is adopted.

This approach has several limitations and assumptions, such that fire growth follows a $\mathrm{t}^{2}$ relationship from ignition to FRS arrival and also that no further increase in fire damage occurs upon FRS arrival. Furthermore, the FRS arrival time does not directly represent the time that the FRS begin to fight the fire, with additional tasks undertaken following first appliance arrival, such as risk assessment, operational planning and preparation of resources [31]. The Fire Brigade Intervention Model (FBIM) [32] provides a detailed breakdown of processes which may occur following FRS arrival, such as the initial determination of the fire location, firefighter travel within the building, the setting up of water supply requirements etc. However, for the purposes of this assessment, the FRS operational time period prior to fighting the fire has not been incorporated (i.e. assumed to be zero), which will provide a degree of conservatism in the estimated values as including this additional time in Eq. 5 would result in a lesser growth rate. 


\section{Table 3 Statistical Parameters for Maximum HRR, for Accidental Fires by Property Type and Room of Fire Origin}

\begin{tabular}{|c|c|c|c|c|c|c|}
\hline \multirow[b]{2}{*}{ Dwelling type } & \multirow[b]{2}{*}{ Room type } & \multirow[b]{2}{*}{$\begin{array}{l}\text { Mean } \\
(\mathrm{kW})\end{array}$} & \multirow[b]{2}{*}{$\begin{array}{l}\mathrm{SD} \\
(\mathrm{kW})\end{array}$} & \multirow[b]{2}{*}{$\begin{array}{l}\text { 95th percentile } \\
\qquad(\mathrm{kW})\end{array}$} & \multicolumn{2}{|c|}{$\begin{array}{l}\text { Equivalent guidance per- } \\
\text { centiles (lognormal) }\end{array}$} \\
\hline & & & & & $\begin{array}{l}\text { BD } 2410 \\
(1000 \mathrm{~kW} \text { to } \\
2500 \mathrm{~kW})\end{array}$ & $\begin{array}{l}\text { SCA guide } \\
(2000 \mathrm{~kW} \\
\text { to } 6000 \mathrm{~kW})\end{array}$ \\
\hline \multirow[t]{4}{*}{ Houses } & Kitchen & 1100 & 2200 & 4000 & $71.2-90.0$ & $86.6-97.6$ \\
\hline & Bedroom & 1900 & 3300 & 6700 & $50.4-78.8$ & $72.8-94.0$ \\
\hline & Living room & 1600 & 3000 & 5600 & $59.9-83.9$ & $79.1-95.5$ \\
\hline & All rooms & 1200 & 2400 & 4400 & $58.0-83.5$ & $78.4-95.6$ \\
\hline \multirow[t]{4}{*}{ Apartments } & Kitchen & 900 & 2000 & 3300 & $77.2-92.4$ & $89.7-98.2$ \\
\hline & Bedroom & 1800 & 3700 & 6400 & $58.2-82.0$ & $77.1-94.4$ \\
\hline & Living room & 1600 & 3000 & 5700 & $58.8-83.4$ & 78.4-95.4 \\
\hline & All rooms & 1000 & 2300 & 3800 & $74.3-91.0$ & 87.9-97.7 \\
\hline All dwellings & All rooms & 1200 & 2400 & 4200 & $70.2-89.2$ & $85.7-97.2$ \\
\hline
\end{tabular}

\section{Results}

\subsection{Maximum Heat Release Rate}

The mean, standard deviation and 95th percentile for the distribution of maximum HRR values is given in Table 3 (to two significant figures), separated by property type and room of fire origin. Also shown is the equivalent percentiles for recommended residential design fires from BD 2410 [5] and the SCA Guide [4], estimated from a lognormal distribution approximation (discussed below). The mean calculated HRR ranges from $900 \mathrm{~kW}$ to $1900 \mathrm{~kW}$ depending on dwelling and room type, with the standard deviation ranging from $2000 \mathrm{~kW}$ to $3700 \mathrm{~kW}$.

The analysis indicates that on average, fires with the greatest HRR occur in bedrooms, followed by the living room and then the kitchen. Marginal differences can be observed between houses and apartments, with larger mean HRRs being estimated for houses. Design fires adopted in BD 2410 align with a 50th to 92nd percentile for maximum HRR, depending upon the room of fire origin and dwelling type, while for the SCA Guide's recommended $2 \mathrm{MW}$ to $6 \mathrm{MW}$ range aligns with the $73 \mathrm{rd}$ to 98 th percentiles. The 95th percentile value sits within the SCA Guide recommended range.

The above parameters can be approximated to a lognormal distribution, with an example given in Fig. 4 below for fires for all dwellings and rooms combined.

\subsection{Fire Growth Rate}

To make a comparison to the method and values determined by Holborn et al., a HRRPUA of $250 \mathrm{~kW} / \mathrm{m}^{2}$ has initially been used in the estimation of fire growth rate. Using Eq. 4, a fire growth rate distribution has been determined with a mean of $0.0014 \mathrm{~kW} / \mathrm{s}^{2}$ and a standard deviation of $0.0049 \mathrm{~kW} / \mathrm{s}^{2}$. This comparatively low value may be partly influenced by the lack of precision in the data for 'igni- 


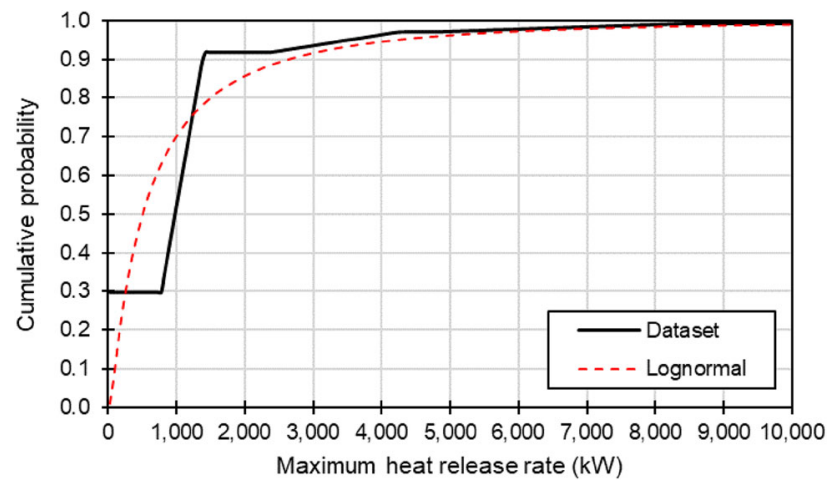

\section{Figure 4. CDF for maximum HRR, all dwellings and rooms.}

tion to discovery' time and 'discovery to call' time provided in the DFD, in contrast to the response time (which is typically in 1 min intervals). The extent of the ignition to discovery and discovery to call time ranges is shown previously in Fig. 2.

Applying the HRRPUA distribution discussed previously to each separate fire incident, the fire growth rate has been determined by property type and room of fire origin. For this, Table 4 provides the mean, standard deviation, 95th percentile and equivalent percentiles for slow, medium and fast $\mathrm{t}^{2}$ growth rates, again estimated from a lognormal distribution.

The mean fire growth rate ranges of $0.0022 \mathrm{~kW} / \mathrm{s}^{2}$ to $0.0034 \mathrm{~kW} / \mathrm{s}^{2}$, depending on dwelling type and room of fire origin, with the standard deviation ranging from $0.0071 \mathrm{~kW} / \mathrm{s}^{2}$ to $0.0132 \mathrm{~kW} / \mathrm{s}^{2}$. The upper bound is closer to the estimations of Holborn et al. than the previous calculation given above. Bedrooms provide the comparatively most severe case for fire growth rate, with a mean growth rate of $0.0032 \mathrm{~kW} / \mathrm{s}^{2}$ and $0.0034 \mathrm{~kW} / \mathrm{s}^{2}$ for houses and apartments, respectively. The 95 th percentile ranges from $0.0089 \mathrm{~kW} / \mathrm{s}^{2}$ to $0.0100 \mathrm{~kW} / \mathrm{s}^{2}$. When considering the $\mathrm{t}^{2}$ growth rates given in PD 7974-1 [6], a slow growth rate represents the 74th to 86th percentiles, medium the 95th to 97 th and fast the 99th to 100th (when rounded to the nearest integer). The 95 th percentile value therefore most closely aligns with a medium growth rate.

The observed distributions from the data broadly align with a lognormal distribution, with an example given in Fig. 5 below for fires for all dwellings and rooms combined.

As noted previously, the data bands for the ignition to discovery to discovery to call times are large, subsequently impacting the precision when determining the resultant FRS arrival time. To indicate the sensitivity of these values, the growth rate has been calculated for fire incidents where there is only immediate ignition to discovery and discovery to call times. This represents an 'immediate' transition from fire ignition to the time that an occupant calls the emergency services, which accounts for $12 \%$ of fire events recorded in the DFD. The resultant parameters are shown in Table 5. 


\section{Table 4}

Statistical Parameters for Growth Rate, for Accidental Fires by Property Type Room of Fire Origin

Equivalent percentiles (lognormal)

\begin{tabular}{llcccccc}
$\begin{array}{l}\text { Dwelling } \\
\text { type }\end{array}$ & \multicolumn{1}{c}{$\begin{array}{c}\text { Room } \\
\text { type }\end{array}$} & $\begin{array}{c}\text { Mean } \\
\left(\mathrm{kW} / \mathrm{s}^{2}\right)\end{array}$ & $\begin{array}{c}\mathrm{SD} \\
\left(\mathrm{kW} / \mathrm{s}^{2}\right)\end{array}$ & $\begin{array}{c}95 \text { th percentile } \\
\left(\mathrm{kW} / \mathrm{s}^{2}\right)\end{array}$ & $\begin{array}{c}\text { Slow } \\
(0.0029)\end{array}$ & $\begin{array}{c}\text { Medium } \\
(0.0117)\end{array}$ & $\begin{array}{c}\text { Fast } \\
(0.0469)\end{array}$ \\
\hline Houses & Kitchen & 0.0026 & 0.0071 & 0.0099 & 79.3 & 96.2 & 99.7 \\
& Bedroom & 0.0032 & 0.0083 & 0.0099 & 73.9 & 95.1 & 99.6 \\
& Living room & 0.0026 & 0.0077 & 0.0100 & 79.1 & 96.1 & 99.6 \\
\multirow{4}{*}{ Apartments } & All rooms & 0.0026 & 0.0071 & 0.0098 & 81.5 & 96.1 & 99.5 \\
& Kitchen & 0.0022 & 0.0132 & 0.0100 & 85.6 & 96.8 & 99.5 \\
& Bedroom & 0.0034 & 0.0116 & 0.0100 & 76.1 & 94.5 & 99.3 \\
& Living room & 0.0029 & 0.0075 & 0.0109 & 76.4 & 95.8 & 99.7 \\
\multirow{4}{*}{ All dwellings } & All rooms & 0.0023 & 0.0119 & 0.0089 & 84.9 & 96.5 & 99.5 \\
& All rooms & 0.0025 & 0.0088 & 0.0098 & 81.5 & 96.1 & 99.5 \\
\hline
\end{tabular}

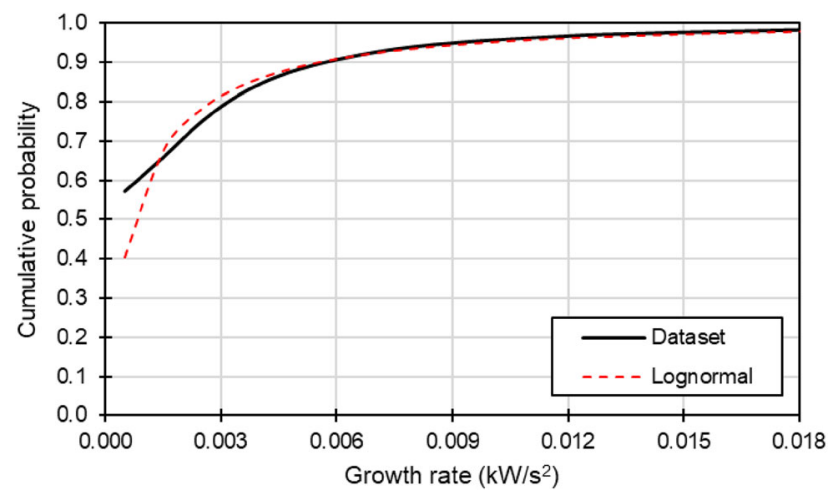

Figure 5. CDF for fire growth rate, all dwellings and rooms.

As would be expected, the calculated growth rate is faster than shown in Table 4, aligning more closely with the growth rate parameters determined previously by Holborn et al. [20], in particular for the mean growth rate. The mean growth rates range from $0.0058 \mathrm{~kW} / \mathrm{s}^{2}$ to $0.0088 \mathrm{~kW} / \mathrm{s}^{2}$, with the standard deviation ranging from $0.0101 \mathrm{~kW} / \mathrm{s}^{2}$ to $0.0335 \mathrm{~kW} / \mathrm{s}^{2}$.

\section{Limitations}

The different approaches used to determine the distributions have several limitations:

- While the DFD is the largest quantity of recent fire event data in England, there is a lack of granularity in data for the fire damage area, as well as for the 


\section{Table 5}

Statistical Parameters for Growth Rate, for Accidental Fires by Property Type Room of Fire Origin, Considering Immediate Ignition to Discovery and Discovery to Call Times Only

\begin{tabular}{|c|c|c|c|c|c|c|c|}
\hline \multirow[b]{2}{*}{$\begin{array}{l}\text { Dwelling } \\
\text { type }\end{array}$} & \multirow[b]{2}{*}{$\begin{array}{l}\text { Room } \\
\text { type }\end{array}$} & \multirow[b]{2}{*}{$\begin{array}{l}\text { Mean } \\
\left(\mathrm{kW} / \mathrm{s}^{2}\right)\end{array}$} & \multirow[b]{2}{*}{$\begin{array}{c}\mathrm{SD} \\
\left(\mathrm{kW} / \mathrm{s}^{2}\right)\end{array}$} & \multirow[b]{2}{*}{$\begin{array}{l}\text { 95th percentile } \\
\qquad\left(\mathrm{kW} / \mathrm{s}^{2}\right)\end{array}$} & \multicolumn{3}{|c|}{$\begin{array}{l}\text { Equivalent percentiles (lognor- } \\
\text { mal) }\end{array}$} \\
\hline & & & & & $\begin{array}{l}\text { Slow } \\
(0.0029)\end{array}$ & $\begin{array}{r}\text { Medium } \\
(0.0117)\end{array}$ & $\begin{array}{l}\text { Fast } \\
(0.0469)\end{array}$ \\
\hline \multirow[t]{4}{*}{ Houses } & Kitchen & 0.0058 & 0.0144 & 0.0217 & 58.3 & 88.9 & 98.6 \\
\hline & Bedroom & 0.0088 & 0.0168 & 0.0314 & 39.2 & 80.8 & 97.6 \\
\hline & Living room & 0.0062 & 0.0140 & 0.0228 & 54.6 & 87.9 & 98.5 \\
\hline & All rooms & 0.0060 & 0.0145 & 0.0225 & 56.4 & 88.3 & 98.5 \\
\hline \multirow[t]{4}{*}{ Apartments } & Kitchen & 0.0062 & 0.0335 & 0.0234 & 69.7 & 90.0 & 97.8 \\
\hline & Bedroom & 0.0079 & 0.0141 & 0.0278 & 40.2 & 82.7 & 98.1 \\
\hline & Living room & 0.0062 & 0.0101 & 0.0211 & 45.6 & 87.3 & 99.0 \\
\hline & All rooms & 0.0063 & 0.0329 & 0.0240 & 68.7 & 89.7 & 97.8 \\
\hline All dwellings & All rooms & 0.0061 & 0.0209 & 0.0235 & 63.0 & 88.9 & 98.1 \\
\hline
\end{tabular}

ignition to discovery and discovery to call times used to estimate the FRS arrival time.

- There is a large variability observed in the results (i.e. large standard deviations and coefficients of variation), which may in part be due to the lack of granularity in the input data. To reduce this variability, it would have been beneficial to specify the maximum HRR and growth rate parameters as a function of the total room area, but this information is not provided in the DFD.

- There are limitations in the assumption that fire damage represents a direct correlation to fire area. While this relationship appears reasonable, literature and quantitative evidence on the topic is lacking.

- The selected HRRPUA distribution has been applied uniformly and does not consider the different types of combustibles which may be present in different rooms, for example where kitchens will typically include different items to living rooms, etc.

- In determining the distributions for fire growth rate, the analyses assume that, in all instances, FRS intervention immediately begins upon first appliance arrival, that this intervention stops fire growth and that the growth from ignition to this time of intervention follows a $\mathrm{t}^{2}$ relationship.

Despite these limitations, the values determined herein appear to indicate some alignment with those determined in previous studies, and existing guidance values are not shown to be disproportionate, for example where the $2 \mathrm{MW}$ to $6 \mathrm{MW}$ range recommended in the SCA Guide [4] aligns with the 73rd to 98th percentiles 
observed from the dataset and where a medium growth rate recommended in PD 7974-1 [6] is calculated to represent a 95th to 97th percentile.

\section{Discussion and Conclusions}

To approximate distribution parameters for fire area, the DFD, which provides data for real fire incidents between 2010 and 2017, has been analysed, considering the fire damage area. Fire damage area has also been considered for different property types, as well as separate room types (kitchen, bedroom and living room), focussing on instances where the fire is limited to the room of origin. The mean fire damage area ranges from $2.02 \mathrm{~m}^{2}$ for apartment kitchen fires (least damage), to $4.36 \mathrm{~m}^{2}$ for bedroom fires in houses (greatest damage). Fire damage area is on average shown to be greater for house fires than for apartment fires.

Applying a distribution for HRRPUA to the fire damage area of each incident, a lognormal distribution for maximum HRR has been calculated. The mean maximum HRR ranges from $900 \mathrm{~kW}$ to $1900 \mathrm{~kW}$, depending on both property type and room of fire origin. Bedroom fires are shown to represent the worst-case (i.e. the greatest mean maximum HRR) and kitchen fires the least severe case of the three different room types.

By equating the FRS arrival time (time from ignition to first appliance arrival) to the growth period of the fire in relation to its maximum HRR, the fire growth rate for each fire incident has been calculated to provide a lognormal distribution of growth rates. This produces a mean growth rate ranging from $0.0022 \mathrm{~kW} / \mathrm{s}^{2}$ to $0.0034 \mathrm{~kW} / \mathrm{s}^{2}$ depending on room of fire origin, with a standard deviation ranging from $0.0071 \mathrm{~kW} / \mathrm{s}^{2}$ to $0.0132 \mathrm{~kW} / \mathrm{s}^{2}$. When considering only incidents with immediate ignition to discovery and discovery to call times, the mean growth rate increases to a range of $0.0058 \mathrm{~kW} / \mathrm{s}^{2}$ to $0.0088 \mathrm{~kW} / \mathrm{s}^{2}$ with a standard deviation range of $0.0101 \mathrm{~kW} / \mathrm{s}^{2}$ to $0.0335 \mathrm{~kW} / \mathrm{s}^{2}$. It is proposed that the adoption of the latter in probabilistic assessments would provide more conservative estimation of fire growth.

The parameters determined herein have the potential to be adopted in future probabilistic assessments of residential designs. Further to this, it is proposed that deterministic fires may also be adopted a result of the analyses. Figure 6 provides design fire HRR curves for different percentiles (80th to 95th), and how these compare relative to fast, medium and slow growing fires. The figure has been separated by houses and apartments. The growth rate for the specified percentiles has been estimated from the lognormal distribution, using the mean and standard deviation values previously specified in Table 4. Similarly, the maximum HRR percentiles have been estimated for parameters given previously in Table 3 .

Of the percentiles presented, the 95th percentile provides the closest placement to a medium growth rate fire. Therefore, as a medium growth rate is consistently recommended in design guidance for use in residential buildings, including PD 7974-1:2003 [8], CIBSE Guide E [9] and EN 1991-1-2 [12], it is proposed that a 95th percentile fire may typically be adopted for deterministic residential analy- 

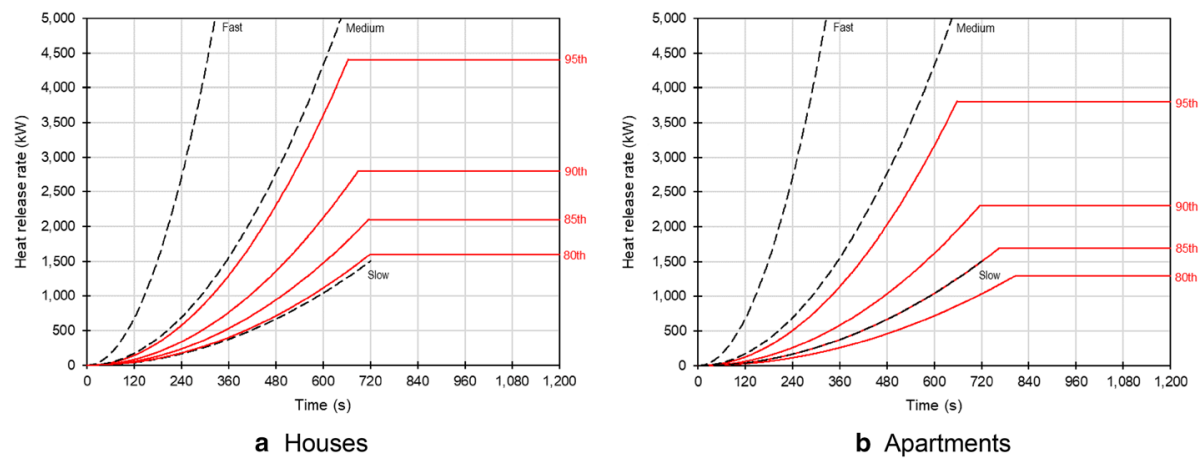

\section{Figure 6. HRR with respect to time, for deterministic design fires.}

ses, with a recommended medium growth rate of $0.0117 \mathrm{~kW} / \mathrm{s}^{2}$ and a maximum HRR in the region of $4400 \mathrm{~kW}$ for houses and $3800 \mathrm{~kW}$ for apartments.

The values given above and in Fig. 6 represent situations where the fire is fuelbed controlled. In practice, there may be circumstances where the maximum HRR and growth of a fire is controlled by ventilation. Therefore, when applying these values, consideration will also need to be given to the available ventilation, such as the window area in the enclosure of fire origin and potential breakage of these windows. Probabilistic distributions for estimated window areas of residential compartments are discussed by $\mathrm{He}$ and Dwyer [33]. Similarly, the probability of glass fallout and window breakage areas for single glazing windows has been analysed by Wong et al. [34]. Whether doors to the room of fire origin are open or closed will also influence the development of the fire. Purser [35] identified that for fires occurring in small enclosures with limited external venting (i.e. doors and windows are closed), the growth of the fire remains restricted. Hopkin et al. [36] assessed internal door closing habits in domestic premises, determining the door closing probabilities for different rooms of origin. These probabilities could be applied in residential design when evaluating the ventilation available from door openings. In addition to ventilation, thought will need to be given the presence of fire safety systems (e.g. sprinkler protection) and their reliability, and the impact this may have on the selected design fire.

\section{Compliance with Ethical Standards}

Conflict of interest The authors declare that they have no conflict of interest.

\section{Open Access}

This article is distributed under the terms of the Creative Commons Attribution 4.0 International License (http://creativecommons.org/licenses/by/4.0/), which permits unrestricted use, distribution, and reproduction in any medium, provided you 
give appropriate credit to the original author(s) and the source, provide a link to the Creative Commons license, and indicate if changes were made.

\section{References}

1. Hadjisophocleous G, Mehaffey J (2016) Fire scenarios. In: SFPE handbook of fire protection engineering, 5th edn. Springer, pp 1262-1288

2. Van Coile R, Hopkin D, Lange D, Jomaas G (2018) The need for hierarchies of acceptance criteria for probabilistic risk assessments in fire engineering. Fire Technol 55(4):1111-1146

3. Home Office (2017) Fire statistics data tables. https://www.gov.uk/government/statistica 1-data-sets/fire-statistics-data-tables. Accessed Jan 2017

4. Smoke Control Association (SCA) (2015) Guidance on smoke control to common escape routes in apartment buildings (flats and maisonettes) revision 2. Federation of Environmental Trade Associations

5. Building Research Establishment (2005) BD 2410, smoke ventilation of common access areas of flats and maisonettes (Project report number 213179). BRE

6. BSI, Published Document PD 7974-1:2019 (2019) Application of fire safety engineering principles to the design of buildings - part 1. Initiation and development of fire within the enclosure of origin (sub-system 1). BSI Standards Publication

7. HM Government, The Building Regulations 2010 (2010) Approved document B (fire safety) volume 2: buildings other than dwellinghouses (2006 edition incorporating the 2010 and 2013 amendments)

8. BSI, Published Document PD 7974-1:2003 (2003) Application of fire safety engineering principles to the design of buildings - part 1. Initiation and development of fire within the enclosure of origin (Sub-system 1). BSI Standards Publication

9. Harrison R, Daniels G, Hallam C (2019) Fire dynamics. In: CIBSE guide E, fire engineering. Chartered Institution of Building Services Engineers

10. Ministry of Business, Innovation \& Employment (2014) C/VM2, verification method: framework for fire safety design, for New Zealand building code clauses C1-C6 protection from fire. New Zealand Government

11. Hopkin C, Spearpoint M, Hopkin D (2019) A review of design values adopted for heat release rate per unit area. Fire Technol 55:1599-1618

12. European Committee for Standardization, EN 1991-1-2 (2002) Eurocode 1: actions on structures - part 1-2. General actions: actions on structures exposed to fire

13. Law M (1980) Air-supported structures: fire and smoke hazards. Arup J 15(3):11-13

14. Klote J, Milke J (2002) Principles of smoke management. American Society of Heating, Refrigerating and Air-conditioning Engineers, Atlanta

15. Fang J, Breese J (1980) NBSIR 80-2120, fire development in residential basement rooms. Center for Fire Research, Washington

16. Morgan H, Hansell G (1984) Fire sizes and sprinkler effectiveness in offices: implications for smoke control design. Fire Saf J 8:187-198

17. Almås J (2018) Quantitative fire risk analysis: a method for defining building-specific risk-adjusted design fires for estimating safe egress time. SFPE Europe 9. https://www.s fpe.org/page/Issue9Feature6. Accessed Jan 2019

18. Yuen WW, Chow WK (2005) A new method for selecting the design fire for safety provision. Fire Sci Technol 24(3):133-149 
19. Theobald C (1977) Growth and development of fire in industrial buildings. Fire Prev Sci Technol 17:4-16

20. Holborn P, Nolan P, Golt J (2004) An analysis of fire sizes, fire growth rates and times between events using data from fire investigations. Fire Saf J 39:481-524

21. Baker G, Wade C, Spearpoint M, Fleishmann C (2013) Developing probabilistic design fires for performance-based fire safety engineering. Procedia Eng 62:639-647

22. Nilsson M, Johansson N, Van Hees P (2014) A new method for quantifying fire growth rates using statistical and empirical data: applied to determine the effect of arson. In: Fire safety science: proceedings of the eleventh international symposium, Canterbury, New Zealand

23. Deguchi Y, Notake H, Yamaguchi J, Tanaka T (2011) Statistical estimations of the distribution of fire growth factor: study on risk-based evacuation safety design method. In: Fire safety science, proceedings of the tenth international symposium, Maryland

24. Home Office (2017) Publishing incident recording system data on the fire and rescue service at an incident level: dwelling fires dataset guidance. The Fire Statistics team

25. BSI, Published Document PD 7974-7:2003 (2003) Application of fire safety engineering principles to the design of buildings - part 7. Probabilistic risk assessment. BSI Standards Publication

26. BSI, Published Document PD 7974-7:2019 (2019) Application of fire safety engineering principles to the design of buildings - part 7. Probabilistic risk assessment. BSI Standards Publication

27. Manes M, Rush D (2018) A critical evaluation of BS PD 7974-7 structural fire response data based on USA fire statistics. Fire Technol 55(4):1243-1293

28. Department for Communities \& Local Government (2015) English housing survey: fire and fire safety. Annual report of England's households and housing stock, 2013-2014, London

29. Williams C, Fraser-Mitchell J, Campbell S, Harrison R (2004) Effectiveness of sprinklers in residential premises. Section 3: Pilot study. Project report number 204505. Building Research Establishment

30. LABC (2018) What is the average house size in the UK?. https://www.labc.co.uk/news/ what-average-house-size-uk. Accessed Jan 2019

31. BSI, Published Document PD 7974-5:2014 (2014) Application of fire safety engineering principles to the design of buildings - part 5. Fire and rescue service intervention (Subsystem 5). BSI Standards Publication

32. Buckley G, Bradborn W, Edwards J, Terry P, Wise S (2000) The fire brigade intervention model. Fire Saf Sci 6:183-194

33. He Y, Dwyer S (2010) Ventilation factors of residential buildings. In: 8th Asia-Oceania symposium on fire science and technology, Melbourne

34. Wong D, Li K, Spearpoint M (2014) A probabilistic model for the fallout area of single glazing under radiant heat exposure. In: Fire safety science 11, Canterbury

35. Purser D (2000) Toxic product yields and hazard assessment for fully enclosed design fires. Polym Int 49:1232-1255

36. Hopkin C, Spearpoint M, Wang Y (2019) Internal door closing habits in domestic premises: results of a survey and their implications on fire safety. Saf Sci 120:44-56

Publisher's Note Springer Nature remains neutral with regard to jurisdictional claims in published maps and institutional affiliations. 